\title{
Less death in the dying
}

\author{
Kornelia Polyak ${ }^{1,2}$, Tsung-Teh Wu ${ }^{3}$, Stanley R. Hamilton ${ }^{2,3}$, \\ Kenneth W. Kinzler ${ }^{2}$ and Bert Vogelstein ${ }^{1,2,4}$ \\ 1 The Howard Hughes Medical Institute, The Johns Hopkins University School of \\ Medicine, 424. N. Bond St. Baltimore, Maryland 21231 \\ 2 Oncology Center, The Johns Hopkins University School of Medicine, 424. N. \\ Bond St. Baltimore, Maryland 21231 \\ ${ }^{3}$ Department of Pathology, The Johns Hopkins University School of Medicine, \\ 424. N. Bond St. Baltimore, Maryland 21231 \\ ${ }^{4}$ corresponding author: The Johns Hopkins Oncology Center, 424 N. Bond \\ Street, Baltimore, MD 21231, USA. tel: (410) 955-8878; fax: (410) 955-0548
}

Received 7.6.96; revised 5.8.96; accepted 15.10.96

Edited by M. Israel

\begin{abstract}
Diseases associated with aging are now the primary causes of death in developed countries. This is in part due to the long recognized exponential association of cancer with age and perhaps to a deterioration of the immune system with advanced age. Both prevention of tumorigenesis and immune function are critically dependent on apoptosis. In this study we examined apoptosis in mice of various age following gamma irradiation. We found a striking agedependent decrease in radiation-induced apoptosis in splenic lymphocytes but not in colorectal epithelial cells. These observations may therefore provide a clue to the decline of immune function with age.
\end{abstract}

\section{Keywords: apoptosis, radiation, aging, immune system}

Abbreviations: TdT, terminal deoxynucleotide transferase; TUNEL, terminal dUTP nick-end labeling

\section{Introduction}

Although the molecular basis of aging is largely unknown, it is likely the result of both genetic and environmental factors (Hart and Turturro, 1992; Cohen, 1994). Many cellular functions, including DNA repair, regulation of cell proliferation, endocrine and immune responses decline with age (Hart and Turturro, 1992; Cohen, 1994; Song et al, 1993; Miller, 1996). Partly as a consequence of these changes, certain diseases such as cancer and immune system disorders occur more frequently in older individuals (Cohen, 1994; Nakamura et al, 1992). Apoptosis has been shown to be involved in many physiologic and pathologic processes, including neoplasia and immune regulation. However, few studies have addressed whether the capacity for programmed cell death varies with age (Monti et al, 1992). To investigate the possibility that the elimination of damaged cells through programmed cell death declines with age, we examined the apoptotic response in mice following gamma irradiation.

\section{Results and Discussion}

One of the most well-studied experimental paradigms for investigating apoptosis involves its induction in lymphocytes by gamma irradiation (Howie et al, 1994). Eight hours after 5 Gy of whole body exposure, mouse spleens were examined with the TUNEL-staining assay (Gavrieli et al, 1992). This assay assesses the fraction of cells with DNA strand breaks, one of the hallmarks of apoptosis. Approximately half the lymphocytes in spleens from young mice (1-4 month old) stained positively following irradiation (Figure 1), with virtually no staining prior to irradiation (not shown). In contrast, many fewer cells in the spleens of older mice (32-34 month old) were stained with TUNEL, though the architecture of the spleen was histologically indistinguishable in the two groups of mice (Figure 1). Mice of the strain used (C57BL/6/CNNia) have a maximal life-span of $35-36$ months.

To quantitate this effect, flow cytometric analysis was performed on the splenocytes. DNA from apoptosing cells degrades, resulting in cells with sub-G1 contents. Representative flow cytometric profiles of spleen cells from irradiated mice are shown in Figure 2a. The spleens from 34 month old mice contained many fewer sub-G1 cells than those from the 4 month old mice, consistent with the TUNEL-staining results. Fluorescence microscopy showed that a significant fraction of the cells from the younger mice exhibited condensed chromatin, and the cells were often micronucleated (Figure 2B). From $40-60 \%$ of the spleen cells from mice 1-22 months of age underwent apoptosis $8 \mathrm{~h}$ after irradiation, while in 28 month old mice, the fraction of apoptotic cells was reduced to $26 \pm 8 \%$, and by 33 months, only $14 \pm 7 \%$ of the cells underwent apoptosis (Figure 3A).

To determine whether this age-related decrease in apoptosis was cell autonomous, we isolated splenocytes from mice of different ages and irradiated them in vitro. The fraction of apoptotic cells in all mice was higher following in vitro irradiation compared to irradiation in vivo, consistent with previous studies (Durand, 1994) (Figure 3B). Nevertheless, the fraction of apoptotic cells was considerably less in 33 month-old mice $(38 \pm 3 \%)$ than in 4 month old mice $(75 \pm 2 \% ; P<0.001)$ following 5 Gy irradiation (Figure $3 \mathrm{~B}$ ). The in vitro assays also afforded the opportunity for dose response analyses, which were difficult to perform in vivo because of the expense and limited availability of the older mice. As shown in Figure 3B, the apoptotic response of the old mice was decreased to that of young mice at all doses, with the most significant difference observed at $5 \mathrm{~Gy}$, the same dose used in vivo. To exclude the possibility that the decreased apoptosis in older mice was a result of increased phagocytosis, macrophages were removed from the isolated splenocytes in some experiments prior to radiation; this depletion had no effect on the fraction of apoptotic cells.

We also attempted to determine whether decreased apoptosis could be observed in the intestinal epithelium of 
H\&E

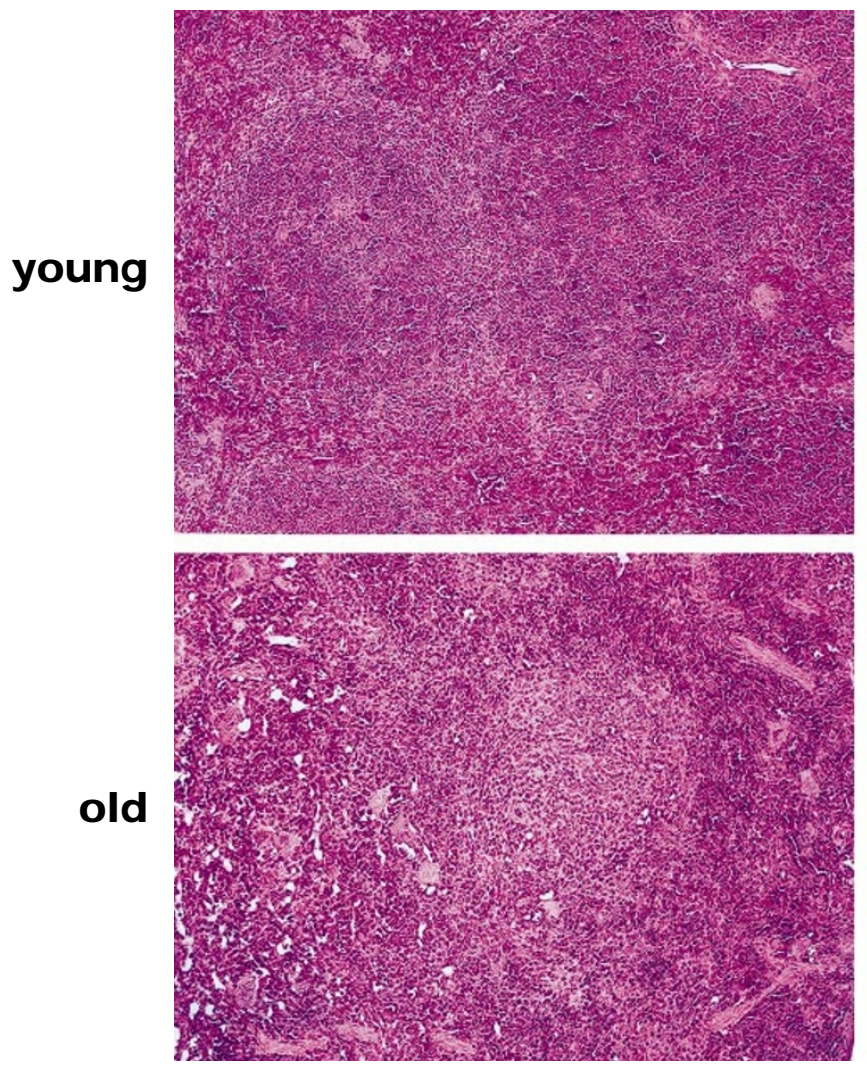

TdT
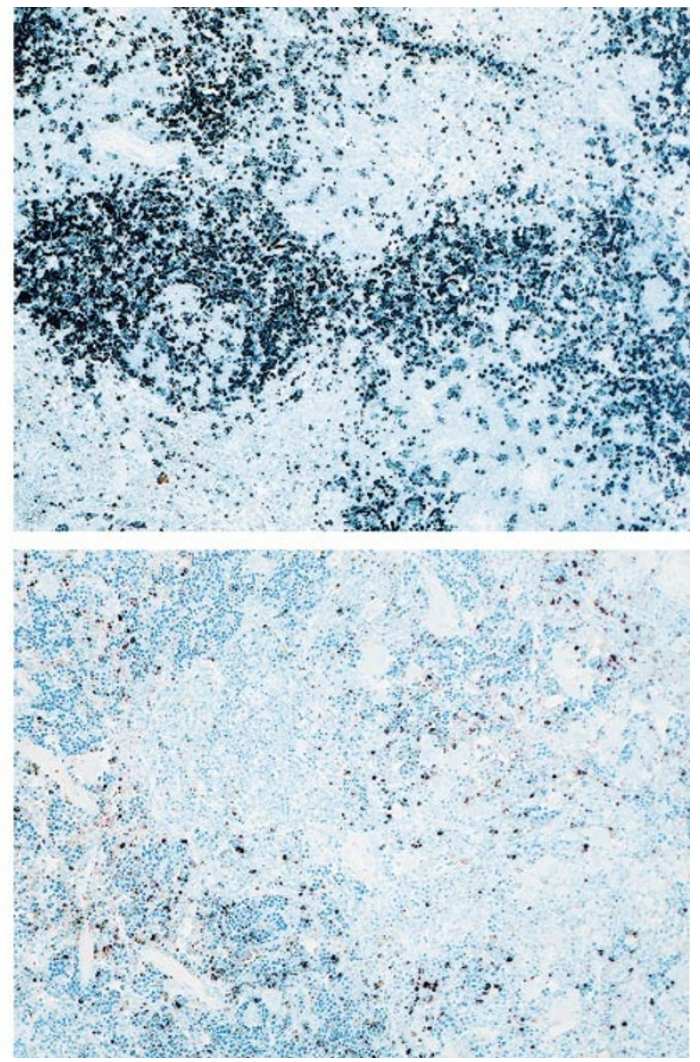

Figure 1 TUNEL staining of irradiated spleen. Hematoxylin-eosin (H\&E) and TUNEL (TdT) stained sections of spleen from young (4 months old) and old (33 months old) mice $8 \mathrm{~h}$ after receiving $5 \mathrm{~Gy}$ of $\gamma$-irradiation. The number of apoptotic cells (stained black on the TdT slides) was significantly lower in the old mice, while the morphology of the spleen was comparable. Similar results were obtained in three independent experiments.

older mice. Classic morphologic criteria following routine hematoxylin and eosin staining was used (Clarke et al, 1994), as the TUNEL assay was found to be a somewhat unreliable indicator of apoptosis in the intestinal tract (Hall et al, 1994 and our unpublished data). In the small intestine, irradiation increased apoptosis from $1 \pm 1$ cell per 100 crypts (in all mice) to $97 \pm 25$ and $111 \pm 32$ cells per 100 crypts in the young and old mice, respectively. Gamma irradiation increased the number of apoptotic cells in the colon to a similar degree, also with no significant differences between old and young mice.

These studies demonstrate a profound difference between irradiation-induced apoptosis of the splenic lymphocytes in young and old mice. The apoptosis 'defect' in the older mice was reproducibly observed in lymphocytes of the spleen, but did not affect the gastrointestinal epithelium. It is perhaps relevant in this regard that radiation-induced apoptosis in the gastrointestinal epithelium is p53-dependent while that of cycling splenocytes is not (Clarke et al, 1993; Lowe et al, 1993; Clarke et al, 1994; Merritt et al, 1994; Strasser et al, 1994; Tamura et al, 1995). The decreased apoptotic response in the older mice was not due to a microenvironmental factor present in the spleen, as similar differences were also observed following irradiation of isolated splenic lymphocytes (Figure 3B).

The mechanism underlying the age-related differences in apoptosis is not known, but two hypotheses can be formulated. First, it is possible that the intrinsic ability of cells to undergo apoptosis declines with age, due to changing patterns in chromatin or in other determinants of gene expression (Issa et al, 1994). Second, it is possible that the decreased apoptosis reflects an age-specific difference in lymphocyte subtypes that populate the spleen (Song et al, 1993). It is known that radiation sensitivities vary with cell type, and it is possible that differences in lymphocytic subtypes could account for our results. The very large differences in apoptosis in the older mice would mandate an equally substantial change in lymphocytic population. It has been shown that non-functional $T$ cells increase with age in both mouse and man, though the molecular and physiologic bases for this dysfunction is not yet clear (Song et al, 1993; Nagel et al, 1988). It will be interesting to determine in the future whether specific lymphocyte subsets, defined by surface markers, occupy a major portion of the aging peripheral immune system, and whether the same cells are deficient in their response to antigenic stimulation and in apoptosis. 
What is the significance of the decreased apoptosis in aging mice? Though this can only be a topic of speculation at present, it is important to point out that the magnitude of the decreased apoptosis was considerable, representing a three- to fourfold reduction, and that a significant difference in the degree of apoptosis was observed at least 6 months prior to death, when mice were 28 months old. These two observations (magnitude and time of occurrence) distinguish the apoptotic-induction differences from many of the other age-related phenomenon that have been reported in the literature (Hart and Turturro, 1992; Cohen, 1994; Song et al, 1993). We hypothesize that an age-related difference in apoptosis induction could make older mice more susceptible to cancer or to autoimmune diseases. Studies to determine whether apoptotic induction varies with age in the human should prove of interest in this regard.

A non-irradiated

irradiated 4 months old

irradiated

22 months old

\section{irradiated 28 months old}

\section{irradiated \\ 33 months old}
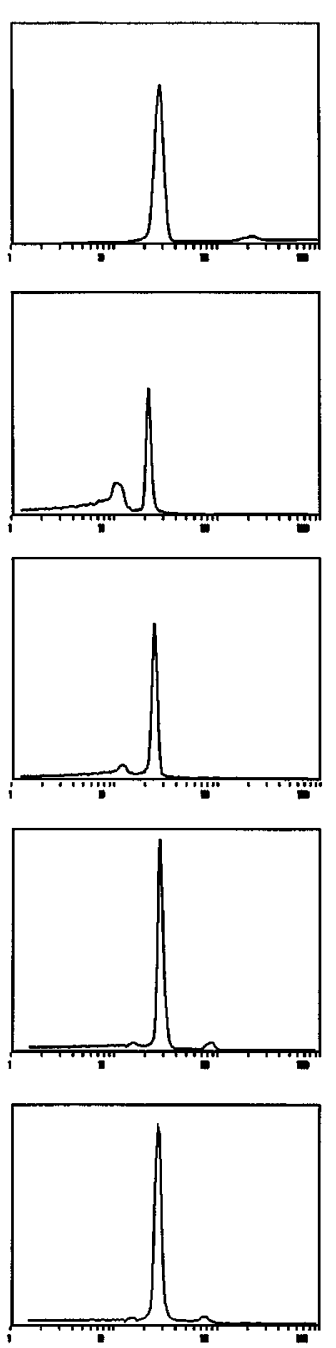

\section{Materials and Methods}

\section{In vivo irradiation and flow cytometry}

Male C57BL/6/CNNia mice of various ages (1-34 months) were irradiated (5 Gy) with a ${ }^{137} \mathrm{Cs} \gamma$ source (dose rate, $0.9 \mathrm{~Gy} / \mathrm{min}$ ) and sacrificed $8 \mathrm{~h}$ later. For morphologic measurements of apoptosis and for TUNEL assays, small intestine, colon and spleen were fixed in $4 \%$ paraformaldehyde in PBS (phosphate buffered saline) at $4{ }^{\circ} \mathrm{C}$ overnight and embedded in paraffin the next day. Three $\mu \mathrm{m}$ sections of the intestine and spleen were either stained with hematoxylin and eosin for morphologic assessment of apoptosis or processed for TUNEL assays. Apoptotic cells were counted in coded slides assessing 100 crypts per section, and triplicate sections were analyzed from each animal (3-4 mice/age group). Analysis was restricted to crypts where the plane of the section included the crypt axis. For flow cytometric analysis, spleen cells were resuspended in
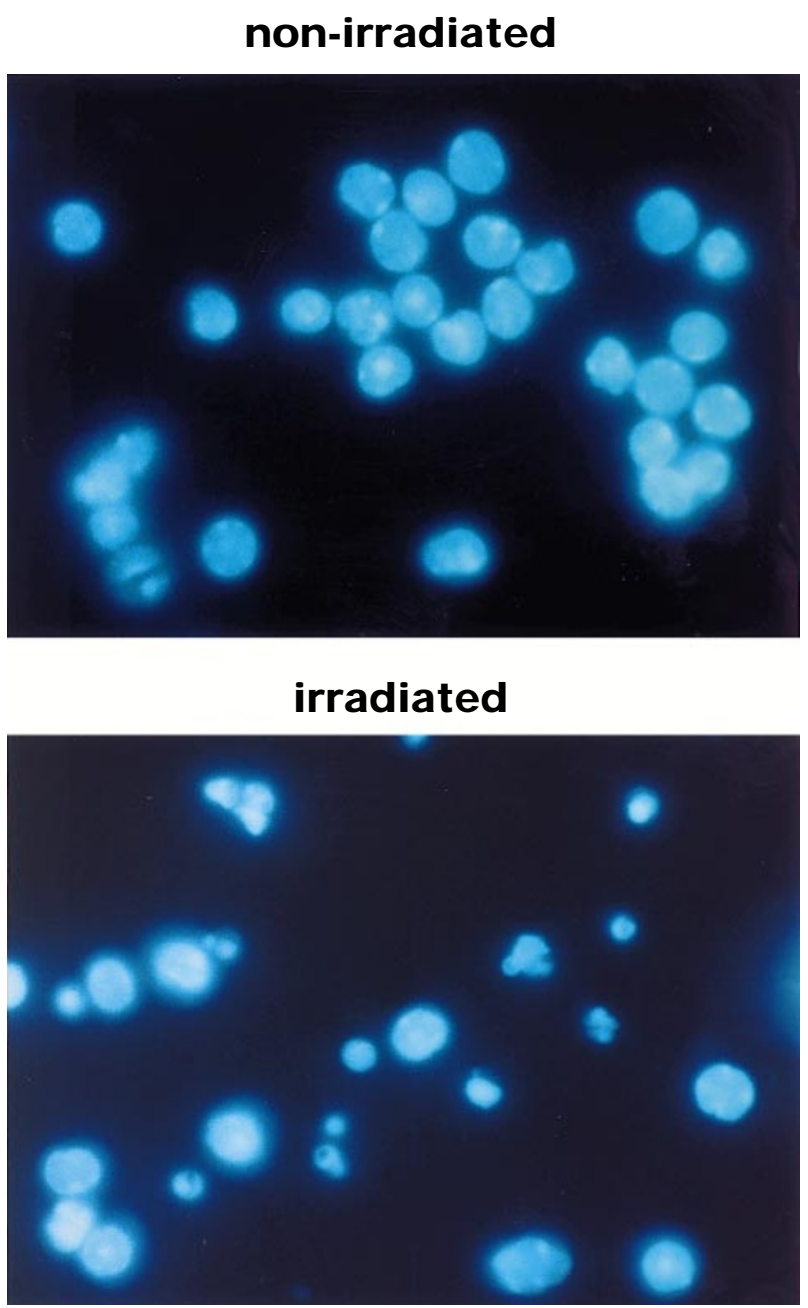

Figure 2 Flow cytometric and microscopic analysis of splenocytes. (A) Flow cytometric analysis of splenocytes isolated from mice of various ages (4-33 months old, as indicated) without treatment (non-irradiated) or $8 \mathrm{~h}$ after $5 \mathrm{~Gy}$ of $\gamma$-irradiation. The splenocytes of non-irradiated mice are almost exclusively in G0/G1 with $2 \mathrm{n}$ DNA content. The apoptotic fraction ( $<\mathrm{G} 1$ ) of cells after irradiation decreases with increasing age. Representative samples from three independent experiments are shown. (B) Splenocytes isolated from mice prior to or after irradiation were fixed, stained with the DNA-binding dye Hoechst 33258, and observed under fluorescence microscopy. Representative cells are shown. Condensed chromatin characteristic of apoptotic cells were observed in the irradiated cells. 
$100 \mu \mathrm{l}$ PBS and were added to $500 \mu \mathrm{l}$ of fix/staining solution containing $0.6 \%$ NP40, 3.7\% formaldehyde, $11 \mu \mathrm{g} / \mathrm{ml}$ Hoechst 33258 in PBS. The fixed and stained cells were directly used for flow cytometry analysis. In each experiment 50,000 cells were counted and the sub-G1 population was quantitated using the Multicycle software package.

\section{TUNEL assay}

Paraffin sections of the spleen or intestine were dried overnight at $80^{\circ} \mathrm{C}$ and deparaffinized in xylene for 30-60 min (three changes) at room temperature. Sections were rehydrated through descending ethanol washes and stored in PBS. Sections were then treated with $60 \mu \mathrm{g} / \mathrm{ml}$ proteinase K (Gibco BRL, DNase and RNase free) in PBS for $15 \mathrm{~min}$ at room temperature. Protease digestion was stopped by consecutive washes in PBS and TdT buffer solutions (5 min each). TUNEL assays were performed at $37^{\circ} \mathrm{C}$ for $1 \mathrm{~h}$ in $1 \times \mathrm{TdT}$ buffer (USB), $150 \mathrm{mM} \mathrm{NaCl}, 2-5 \mu \mathrm{M}$ biotin 16-dUTP (Boehringer) and 50-100 U/ $\mathrm{ml} \mathrm{TdT} \mathrm{(USB).} \mathrm{After} \mathrm{washing} \mathrm{in} \mathrm{PBS,} \mathrm{labeled} \mathrm{cells} \mathrm{were} \mathrm{visualized} \mathrm{with}$

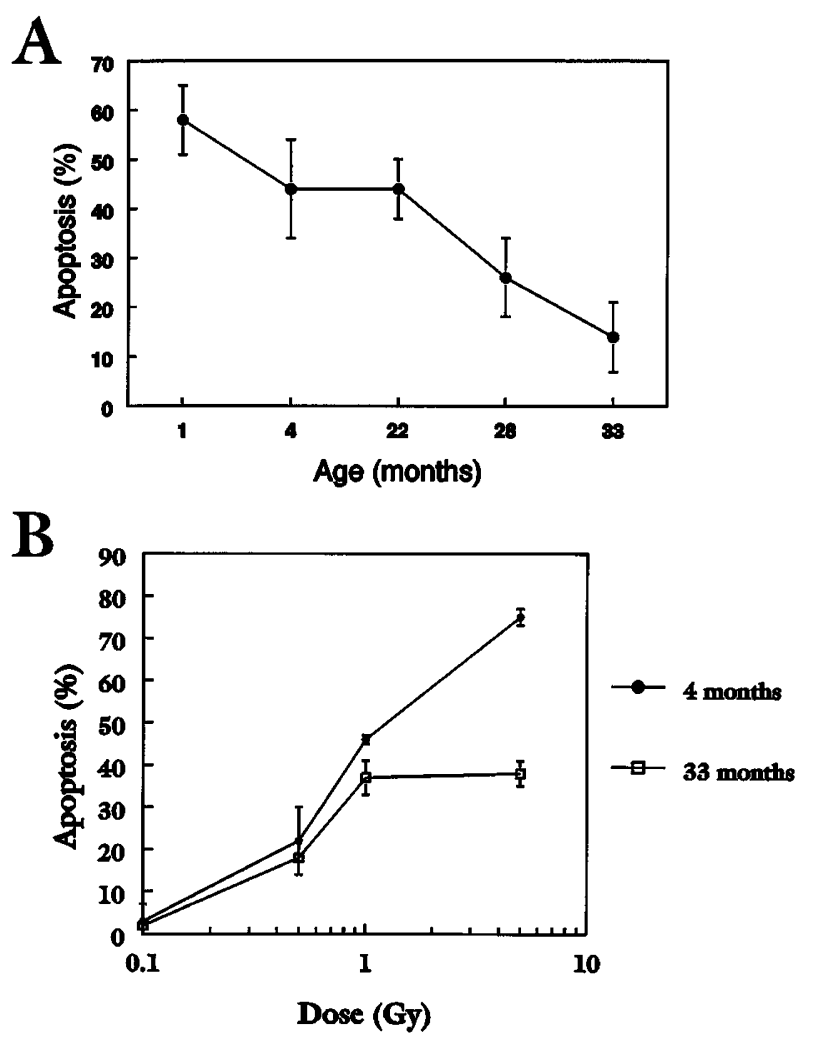

Figure 3 Relationship between apoptosis and age. (A) The fraction of apoptotic cells $\left(<\mathrm{G}_{1}\right)$ was quantitated based on flow cytometry analysis of splenocytes isolated from mice of various ages $8 \mathrm{~h}$ after $5 \mathrm{~Gy}$ of $\gamma$-irradiation. Numbers are based on results of two independent experiments, each experiment employing 5 mice/age group. Error bars represent standard deviations. The difference in apoptosis between young (1-4 months) and old (28-33 months) mice was highly statistically significant $(P<0.0001)$. (B) Splenocytes were isolated from mice of various ages and irradiated in vitro as described in Materials and Methods. Flow cytometric analysis was performed $8 \mathrm{~h}$ after radiation and apoptotic cells $(<\mathrm{G} 1)$ were quantitated. Numbers are based on results of two independent experiments each employing 2 mice/age group. Error bars represent standard deviations of the mean. The difference in apoptosis between the two age groups approached statistical significance at $1 \mathrm{~Gy}(\mathrm{P} 0.08)$ and reached statistical significance at $5 \mathrm{~Gy}(P<0.01)$. the $A B C$ horseradish peroxidase method (Vector laboratories, Burlingame, CA). Sections were counterstained with $0.5 \%$ methyl green, dehydrated, then mounted in Cytoseal 60 (Stephens Scientific, Riverdale, N.J.).

\section{In vitro irradiation and flow cytometric analysis}

Splenic lymphocytes were isolated from untreated animals essentially as described (Kruisbeek, 1993) using Histopaque-1083 (Sigma). Freshly isolated splenocytes were resuspended at $1 \times 10^{6} \mathrm{cells} / \mathrm{ml}$ in RMPI-1640 medium supplemented with $10 \%$ fetal bovine serum and irradiated using a ${ }^{137} \mathrm{Cs}$ source. In some experiments phagocytic cells were removed from the splenocyte suspension by incubating the cells in T75 tissue culture flasks for $1 \mathrm{~h}$. Non-adherent cells were used for subsequent treatment and analysis (Waldman et al, 1995). Cells were collected by centrifugation $8 \mathrm{~h}$ after irradiation and prepared for flow cytometry as described above.

\section{Acknowledgements}

We thank Jim Flook for expert assistance with flow cytometric analysis. This work was supported by the Clayton Fund and NIH grants CA35494, CA 43460, CA57345, and CA62924. B.V. is an investigator of the Howard Hughes Medical Institute.

\section{References}

Clarke AR, Prudie CA, Harrison DJ, Morris RG, Bird CC, Hooper ML and Wyllie AH (1993) Thymocyte apoptosis induced by p53-dependent and independent pathways. Nature 362: 849-852

Clarke AR, Gledhill S, Hooper ML, Bird CC and Wyllie AH (1994) p53 dependence of early apoptotic and proliferative responses within the mouse intestinal epithelium following gamma-irradiation. Oncogene 9: 1767-1773

Cohen HJ (1994) Biology of aging as related to cancer. Cancer 74: 2092-2100

Durand RE (1994) The influence of microenvironmental factors during cancer therapy. In Vivo 8: 691-702

Gavrieli Y, Sherman Y and Ben-Sasson SA (1992) Identification of programmed cell death in situ via specific labeling of nuclear DNA fragmentation. J. Cell Biol. 119: 493-501

Hall PA, Coates PJ, Ansari B and Hopwood D (1994) Regulation of cell number in the mammalian gastrointestinal tract: the importance of apoptosis. J. Cell Sci. 107: 3569-3577

Hart RW and Turturro A (1992) Overview of cancer and aging: a mechanistic perspective. Exp. Gerontol. 27: 567-574

Howie SE, Harrison DJ and Wyllie AH (1994) Lymphocyte apoptosis - mechanisms and implications in disease. Immunol. Rev. 142: 141-156

Issa JP, Ottaviano YL, Celano P, Hamilton SR, Davidson NE and Baylin SB (1994) Methylation of the oestrogen receptor $\mathrm{CpG}$ island links ageing and neoplasia in human colon. Nat. Genet. 7: 536-540

Kruisbeek AM (1993) Isolation of mouse mononuclear cells. In Current Protocols in Immunology, in Coligan JE, Kruisbeek AM, Margulies DH, Shevah EM, Strober W, eds. (New York: Wiley Interscience) pp. 3.1.3-3.1.5

Lowe SW, SchmittEM, Smith SW, Osborne BA and Jacks T (1993) p53 is required for radiation-induced apoptosis in mouse thymocytes. Nature 362: 847-849

Merritt AJ, Potten CS, Kemp CJ, Hickman JA, Balmain A, Lane DP and Hall PA (1994) The role of p53 in spontaneous and radiation induced apoptosis in the gastrointestinal tract of normal and p53-deficient mice. Cancer Res. 54: 614617

Miller RA (1996) The aging immune system: primer and prospectus. Science 273: $70-74$

Monti D, Troiano L, Tropea F, Grassilli E, Cossarizza A, Barozzi D, Pelloni MC, Tamassia MG, Bellomo G and Franceshi C (1992) Apoptosis - programmed cell death: a role in the aging process? Am. J. Cli. Nutr. 55: 1208S-12014S 
Nagel JE, Chopra RK, Chrest FJ, Mc Coy MT, Schneider EL, Holbrook NJ and Alder WH (1988) Decreased proliferation, interleukin 2 synthesis, and interleukin 2 receptor expression are accompanied by decreased mRNA expression in phytohemagglutinin-stimulated cells from elderly donors. J. Clin. Invest. 81: $1096-1102$

Nakamura K, Kuramoto K, Shibasaki K, Shumiya S and Ohtsubo K (1992) Agerelated incidence of spontaneous tumors in SPF C57BL/6 and BDF1 mice [in Japanese]. Jikken Dobutsu 41: 279-285

Song L, Kim YH, Chopra RK, Proust JJ, Nagel JE, Nordi AA and AdlerWH (1993) Agerelated effects in T cell activation and proliferation. Exp. Gerontol. 28: 313-321
Strasser A, Harris AW, Jacks T and Cory S (1994) DNA damage can induce apoptosis in proliferating lymphoid cells via p53-independent mechanisms inhibitable by Bcl-2. Cell 79: 329-339

Tamura T, Ishihara M, Lamphier MS, Tanaka N, Oishi I, Aizawa S, Matsuyama T, Mak TW, Taki S and Taniguchi T (1995) An IRF-1-dependent pathway of DNA damage-induced apoptosis in mitogen activated T lymphocytes. Nature 376: $596-599$

Waldman T, Kinzler KW and Vogelstein B (1995) p21 is necessary for the p53mediated G(1) arrest in human cancer cells. Cancer Res. 55: 5187-5190 